\title{
Morphological and molecular characterization of a marine fish trypanosome from South Africa, including its development in a leech vector
}

\author{
Polly M Hayes ${ }^{1,2}$, Scott P Lawton ${ }^{2}$, Nico J Smit ${ }^{3 *}$, Wendy C Gibson ${ }^{4}$ and Angela J Davies ${ }^{2,3}$
}

\begin{abstract}
Background: Trypanosomes are ubiquitous blood parasites of marine and freshwater fishes, typically transmitted by aquatic leeches. Phylogenetic studies have been dominated by examples derived from freshwater fishes, with few marine representatives. Furthermore, life cycle studies on marine fish trypanosomes have focused on those of the northern hemisphere. In this investigation, we have examined the life cycle and molecular taxonomy of a marine fish trypanosome from South Africa.
\end{abstract}

Methods: To locate trypanosome stages, leeches were removed from fishes captured on the west and south coasts of South Africa, and fish blood films and leech squashes were Giemsa-stained and screened; leeches were also examined histologically. To determine whether trypanosome stages in fishes and leeches were of the same genotype, DNA was extracted from Giemsa-stained fish blood films and leech squashes, and from fish whole blood. Fragments of the 18S rRNA gene were amplified by PCR using trypanosome-specific primers and sequenced. Resulting sequence data were compared with each other and with published trypanosome 18S rDNA sequences, and used for phylogenetic analysis.

Results: Trypanosomes were detected in blood films from fishes of the families Clinidae, Blenniidae and Gobiidae. The flagellates ranged in size and staining properties within the films and across fish hosts. In squashes and histological sections of adult and juvenile leeches, identified as Zeylanicobdella arugamensis, trypanosome developmental stages were predominantly slender epimastigotes. Sequence data showed that trypanosomes derived from fishes were identical, irrespective of whether they were small or large forms; sequences derived largely from leech epimastigotes were also identical to those obtained from fish trypanosomes. Fish and leech trypanosome sequences fell into a marine fish aquatic clade, and aligned most closely with two trypanosome sequences from marine fishes off Norway.

Conclusions: Combined morphological and molecular methods indicate that the trypanosomes examined here represent a single pleomorphic species, rather than the three species described originally. This species is identified as Trypanosoma nudigobii Fantham, 1919 with the leech Z. arugamensis as its vector, and T. capigobii Fantham, 1919 and T. blenniclini Fantham, 1930 are regarded as junior synonyms of the species. Phylogenetic analysis establishes its affinity with marine fish trypanosomes off Norway.

Keywords: Fishes, Leeches, Trypanosomes, Trypanosoma nudigobii, Life cycle, 18S rDNA sequences

\footnotetext{
* Correspondence: nico.smit@nwu.ac.za

${ }^{3}$ Water Research Group (Ecology), Unit for Environmental Sciences and Management, North-West University, Potchefstroom Campus, Potchefstroom 2520, South Africa

Full list of author information is available at the end of the article
} 


\section{Background}

The life cycles of most fish trypanosomes (Euglenozoa; Kinetoplastea) are unknown, but leeches have been identified as the invertebrate hosts and vectors for some from freshwater fishes [1]. Leeches are also the likely vectors for marine fish trypanosomes, especially in the northern hemisphere [2-9], although proof of such transmission is often lacking.

Prior to 2006, knowledge of marine fish trypanosomes in South Africa was limited to three named species, based on their vertebrate stages $[10,11]$, with additional unnamed trypanosomes noted in brackish water fishes of the family Mugilidae from the region [12,13]. Of the marine species, Trypanosoma nudigobii Fantham, 1919 and the smaller Trypanosoma capigobii Fantham, 1919 were described from the gobiid, Caffrogobius nudiceps (Valenciennes, 1837) (syn. Gobius nudiceps), at Kalk Bay on the southern coast [10]. Later, Trypanosoma blenniclini Fantham, 1930 was recorded from the blenniid, Parablennius cornutus (Linnaeus, 1758) (syn. Blennius cornutus) and the clinid Blennophis anguillaris (Valenciennes, 1836) (syn. Clinus anguillaris) [11]. In addition, larger forms of T. capigobii were reported in C. nudiceps close to Kalk Bay, at St James [11]. However, in 2006, Yeld and Smit [14] described a trypanosome, Trypanosoma haploblephari Yeld and Smit, 2006, from marine elasmobranchs in South Africa, although no developmental stages were detected in leeches taken from the captured fishes. Furthermore, Hayes et al. [15] reported briefly trypanosomes resembling those of Fantham [10,11], parasitizing several small marine teleosts in South Africa, with their possible development in an intertidal leech.

In addition to fish trypanosome life cycles often proving problematic to resolve, phylogenetic relationships among these flagellates are often uncertain [16-18]. Freshwater species predominate phylogenetic studies of fish trypanosomes, using $18 \mathrm{~S}$ rDNA sequences, with only a few marine species included, such as Trypanosoma boissoni Ranque, 1973 and Trypanosoma senegalense Ranque, 1973 from the sea off Senegal, and Trypanosoma pleuronectidium Robertson, 1906 and Trypanosoma murmanense Nikitin, 1927, from the sea off Norway [16,18-20]. To date, studies of phylogenetic relationships among fish trypanosomes in southern Africa are limited to freshwater species [17].

In the present study, the marine trypanosomes from teleost and leech hosts reported briefly from South Africa by Hayes et al. [15] are fully characterized, together with additional trypanosome material from both types of host taken from a new collection site in the same region. Morphological and molecular methods are applied to resolve the life cycle of a single fish trypanosome, with its phylogenetic relationships inferred from partial $18 \mathrm{~S}$ rDNA sequences. Finally, comparisons are made between this material and the three marine fish trypanosomes recorded by Fantham $[10,11]$. The work is novel in that it is the first to identify the vertebrate and invertebrate hosts of a marine fish trypanosome using both morphological and molecular methods.

\section{Methods}

\section{Fishes, leeches and their initial screening}

From Fantham's records [10,11] and those of Hayes et al. [15] it appeared that small intertidal fishes of the teleost families Clinidae, Blenniidae and Gobiidae were mostly likely to be parasitized by the trypanosomes under consideration. Therefore, in the current study, trypanosome material relating to these fish families dating from 2003 [15] was re-examined, and newer 2008, 2010 and 2013 samples were studied, with the same focus.

Material was re-assessed from 51 host fishes, including Clinus agilis Smith, 1931 and Clinus cottoides Valenciennes, 1836 (Clinidae), and Parablennius cornutus (Linnaeus, 1758) (Blenniidae), collected from rock pools at Mouille

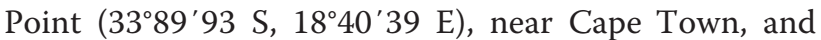
Koppie Alleen (3446'87 S, 2053'86 E), De Hoop Nature Reserve, on the west (Atlantic Ocean) and south (Indian Ocean) coasts of South Africa respectively, in September and October 2003 [15] (Table 1). Further rock pool fishes ( $\mathrm{n}=41)$, including Caffrogobius nudiceps (Gobiidae), and Clinus superciliosus (Linnaeus, 1758), Clinus taurus Gilchrist \& Thompson, 1908 and Pavoclinus graminis (Gilchrist \& Thompson, 1908) (Clinidae), were captured at Tsitsikamma National Park (3402'07 S, 23⒏'60 E), also on the south coast (Indian Ocean) of this region, in April 2008, 2010, and 2013 (Table 1) using the methods of Hayes et al. [15], and transported live to a field laboratory.

As in the earlier study, fishes were anaesthetised with clove oil [21] and then examined for leeches, Zeylanicobdella arugamensis De Silva, 1963 [15]. These annelids ( $\mathrm{n}=18$, including 10 from 2003 and 8 from 2008, see Table 1) were located mainly on the pectoral and pelvic fins of host fishes, and were removed and maintained singly, or in groups, in fresh seawater [15]. Juvenile gnathiid isopods identified as Gnathia africana Barnard, 1914 [22], were found on the fishes at Tsitsikamma, but since no trypanosome stages had been found in these crustaceans previously [15], they played no further part in the current study and were used for other research purposes.

Blood films from 51 fishes captured at Mouille Point and at Koppie Alleen in 2003 [15] were re-examined. Further films were prepared from anaesthetized fishes following removal of blood from the heart or caudal vein using a 23 gauge needle with an attached $1 \mathrm{ml}$ syringe, or by snipping a few gill filaments. Blood films were then fixed in absolute methanol and stained with conventional Giemsa's stain [15]. Whole blood samples, also extracted by needle and syringe, were placed in sterile $2 \mathrm{ml}$ tubes and fixed in $70 \%$ molecular grade ethanol ( one third whole blood to 
Table 1 Study sites with dates, fish species with size details, trypanosome and leech prevalences

\begin{tabular}{|c|c|c|c|c|c|c|c|}
\hline \multirow[t]{2}{*}{ Site and date } & \multicolumn{3}{|c|}{ Fishes } & \multirow{2}{*}{$\begin{array}{l}\text { Prevalence of } \\
\text { trypanosomes } \\
\text { in fishes }\end{array}$} & \multirow{2}{*}{$\begin{array}{l}\text { Prevalence of fishes with } \\
\text { leeches (total number of } \\
\text { leeches; adults or juveniles) }\end{array}$} & \multirow{2}{*}{$\begin{array}{l}\text { Prevalence of trypanosome } \\
\text { stages in leeches } \\
\text { (leech adults or juveniles) }\end{array}$} & \multirow[t]{2}{*}{ Reference } \\
\hline & Species & No & $\mathrm{TL} \pm \mathrm{SD}$ (range) in $\mathrm{cm}$ & & & & \\
\hline Mouille Point October 2003 & Clinus agilis & 1 & 8 & $1 / 1(100 \%)$ & $0 / 1$ & - & {$[15]$} \\
\hline \multirow[t]{2}{*}{ Koppie Alleen October 2003} & Clinus cottoides & 47 & $6.4 \pm 1.8(2.6-8.9)$ & $10 / 47(21 \%)$ & 9/47 (19\%) (9 leeches; 8 adults, 1 juvenile) & 8/9 (89\%) (7 adults, 1 juvenile) & {$[15]$} \\
\hline & Parablennius cornutus & 3 & $7.2,8.4,9.1$ & $2 / 3(67 \%)$ & 1/3 (33\%) (1 leech; 1 adult) & 1/1 (100\%) (1 adult) & [15] \\
\hline \multirow[t]{4}{*}{ Tsitsitkamma April 2008} & Caffrogobius nudiceps & 6 & $11.0 \pm 0.9(10.1-12.6)$ & $0 / 6(0 \%)$ & $0 / 6(0 \%)$ & - & This study \\
\hline & Clinus superciliosus & 16 & $14.0 \pm 2.8(6.4-17.9)$ & $11 / 16(69 \%)$ & 4/16 (25\%) (7 leeches; 4 adults, 3 juveniles) & 3/7 (43\%) ( 2 adults, 1 juvenile) & This study \\
\hline & Clinus taurus & 2 & $20.6,15.4$ & $1 / 2(50 \%)$ & 1/2 (50\%) (1 leech; adult) & 1/1 (100\%) (1 adult) & This study \\
\hline & Pavoclinus graminis & 1 & 13.1 & $0 / 1(0 \%)$ & $0 / 1(0 \%)$ & - & This study \\
\hline \multirow[t]{2}{*}{ Tsitsitkamma April 2010} & Clinus superciliosus & 5 & $13.1 \pm 2.2(9.1-14.9)$ & $3 / 5(60 \%)$ & $0 / 5(0 \%)$ & - & This study \\
\hline & Clinus taurus & 1 & 23.3 & 0/1 (0\%) & 0/1 (0\%) & - & This study \\
\hline Tsitsitkamma April 2013 & Clinus superciliosus & 10 & $10.7 \pm 2.18(7.8-14.2)$ & 0/10 (0\%) & $0 / 10(0 \%)$ & - & This study \\
\hline TOTAL & & 92 & & 28/92 (30\%) & 15/92 (16\%) (18 leeches; 14 adults, 4 juveniles) & 13/18 (11 adults, 2 juveniles) & \\
\hline
\end{tabular}

No number of fishes, $T L$ fish total length and range in parenthesis, $S D$ standard deviation. Reference to the previous and current study. 
two thirds ethanol), sealed, frozen at $-20^{\circ} \mathrm{C}$, and processed subsequently for molecular analysis (see below). Giemsastained squashes from 15 leeches (11 adults and 4 juveniles) were prepared up to 32 days post feeding (d.p.f.) on fishes, and haematoxylin and eosin-stained histological sections of a further 3 leeches ( 2 adults and 1 juvenile) were processed at $\sim 1$ d.p.f. [15].

Fish blood films, leech squashes and histological sections were all screened with brightfield or differential interference contrast (DIC) facilities on Nikon Eclipse 80i (Nikon, Tokyo, Japan) or Zeiss Axioskop (Carl Zeiss, Germany) photomicroscopes. Images of films, squashes and sections were then captured with a Nikon DS-5 M camera and Nikon NIS 2.10 image analysis system (Nikon), calibrated to a stage micrometer.

\section{DNA extraction, PCR and sequence analysis}

Following screening, and just prior to DNA extraction, Giemsa stained fish blood films and leech squashes, positive for trypanosome stages, were scraped separately using sterile scalpel blades into $1.5 \mathrm{ml}$ microcentrifuge tubes. DNA from these, and from 8 whole blood samples fixed in $70 \%$ ethanol, was extracted using a QIAamp DNA mini kit or Qiagen DNeasy blood and tissue kit (QIAGEN Ltd., UK) according to the manufacturers' instructions. Once extracted, purified DNA was used as a template for PCR (polymerase chain reaction), using trypanosome-specific $18 \mathrm{~S}$ rRNA gene primers $\mathrm{B}\left(5^{\prime}-\mathrm{C}\right.$ GAACAACTGCCCTATCAGC-3') and I (5'-GACTACA ATGGTCTCTAATC-3') to generate sequences of approximately $900 \mathrm{bp}$ [23]. PCR conditions were as follows: initial denaturation at $95^{\circ} \mathrm{C}$ for $5 \mathrm{~min}$, followed by 35 cycles of $95^{\circ} \mathrm{C}$ for $1 \mathrm{~min}, 50^{\circ} \mathrm{C}$ for $1 \mathrm{~min}, 72^{\circ} \mathrm{C}$ for $2 \mathrm{~min}$, and a final extension time of $10 \mathrm{~min}$ at $72^{\circ} \mathrm{C}$. Sequencing reactions were performed either on PCR products directly, or on gel purified products using an Applied Biosystems Big Dye Kit version 1.1 and run on an Applied Biosystems 3730 DNA Analyzer. Resultant sequences were viewed and edited in Bioedit 7.5.0.2 [24] and identified as trypanosomes using the Basic Local Alignment Search Tool (BLAST) (http://www.ncbi.nlm.nih.gov/blast/Blast.cgi).

\section{Phylogenetic analysis of sequence data}

Published trypanosome $18 \mathrm{~S}$ rDNA sequences representing 27 trypanosome species which parasitize freshwater and marine animals including fishes, amphibians and reptiles, as well as the monotreme mammal, the duck-billed platypus, were retrieved from GenBank (http://www.ncbi.nlm. nih.gov/blast/Blast.cgi) and aligned with the trypanosome sequences generated from fish blood and leeches in this study. Alignments were performed using the MUSCLE sequence alignment tool (http://www.ebi.ac.uk) and visualised in Bioedit where any final minor adjustments were performed by eye. All phylogenetic analyses were undertaken using MEGA5 [25]. Neighbour Joining (NJ) phylogenies were constructed using the Kimura 2 parameter (K2P) for pairwise distance calculations, as well as a Maximum Composite Likelihood model used to verify the tree topology produced by the K2P model. Character based phylogenetic analyses were also performed including the construction of maximum parsimony (MP) phylogenies as well as maximum likelihood (ML) phylogenies. The ML analysis was performed under the conditions of the $\mathrm{K} 2 \mathrm{P}$ model with a four category gamma $(G)$ distribution, as determined using the model test function also in MEGA version 5 [25]. Bootstrap analysis was undertaken with 500 replicates and only those values $>50$ were shown. In all of the analyses Trypanosoma lewisi [GenBank:AJ223566], Trypanosoma grayi [GenBank:AJ223565] and Trypanosoma avium [GenBank: U39578] sequences formed the outgroup.

This study received the relevant ethical approval (North-West University ethics approval no: NWU-0009512-A4).

\section{Results}

\section{General observations on blood parasites in fishes and leeches}

The identity, number and length of fishes with trypanosomes $(n=51)$, collected at Mouille Point and Koppie Alleen in October 2003, and the prevalence of these flagellates in the fishes, as well as leeches, are detailed in Hayes et al. [15], but summarized in Table 1. Of the three fish species parasitized, 1/1 Clinus agilis from Mouille Point, and 10/47 Clinus cottoides and 2/3 Parablennius cornutus from Koppie Alleen had trypanosomes, as well as 9/10 specimens of the leech Zeylanicobdella arugamensis taken from $C$. cottoides and P. cornutus at Koppie Alleen.

A further 41 fishes belonging to four species in three genera were collected from Tsitsikamma in April of 2008, 2010 and 2013 (see Table 1). Of these, Caffrogobius nudiceps and Pavoclinus graminis were not found to be parasitized by trypanosomes or leeches, but a total of $14 / 26$ Clinus superciliosus and 1/3 Clinus taurus contained the flagellates, as well as 3/7 leeches from C. supercilosus and one leech from C. taurus (see Table 1). Blood films from fishes and leech squashes at Tsitsikamma, as previously at Mouille Point and Koppie Alleen [15,26], also contained other haematozoans, but these will be reported elsewhere (Davies et al. in preparation).

\section{Description of trypanosome stages in fishes}

These descriptions are taken from re-assessed Mouille Point and Koppie Alleen (2003) material, as well as from blood films prepared in 2008 and 2010 at Tsitsikamma. No trypanosomes were found in 2013 samples from Tsitsikamma. In each trypanosome positive blood film $\sim 5$ of these flagellates were normally present, and they varied in size and staining properties. As Fantham [10,11] 
described, we observed "small" and "large" trypanosomes (blood trypomastigotes) in fish blood films (Figure 1A-H) and, because our largest trypanosomes approached $100 \mu \mathrm{m}$ in total body length (excluding the free flagellum), we have defined, for ease of comparison with Fantham's trypanosomes, a total body length of $49.9 \mu \mathrm{m}$, or less, as a "small trypanosome" and of $50 \mu \mathrm{m}$, or more, as a "large trypanosome". The morphometric data [27] for these "small" and "large" trypanosome types are shown in Table 2.

Large trypanosomes dominated infections in $C$. agilis from Mouille Point, with one small form with two kinetoplasts suspected to be a division stage (Figure 1A); a similar, single, dividing form was also seen in P. cornutus at Koppie Alleen. Small and large trypanosomes formed mixed populations in most smears examined from

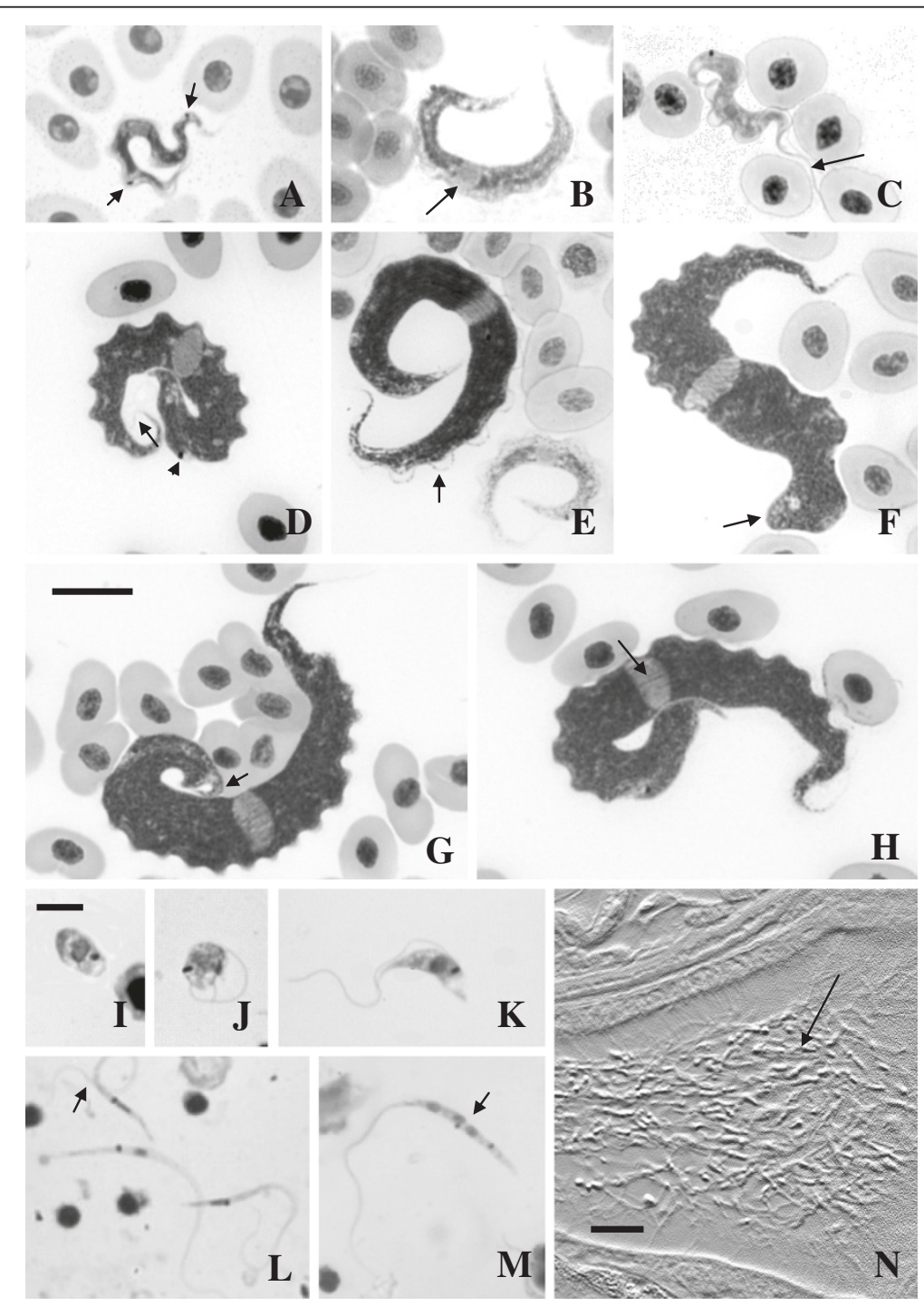

Figure 1 Brightfield images of Giemsa stained fish blood films (A-H) and leech squashes (I-M); differential interference contrast image of haematoxylin and eosin stained histological section through a leech (N). A: Small, likely dividing trypanosome with two kinetoplasts (arrows) from Clinus agilis at Mouille Point. B: Small trypanosome showing the nucleus (arrow) from Clinus cottoides at Koppie Alleen. C: Small trypanosome demonstrating the flagellum from Parablennius cornutus at Koppie Alleen. D: Large trypanosome with faintly stained flagellum (arrow) and showing the position of the kinetoplast (arrowhead), from Clinus superciliosus at Tsitsikamma. E: Large trypanosome (left) demonstrating the undulating membrane (arrow) and small form (right) from C. superciliosus at Tsitsikamma. F: Large form with bluntly rounded posterior (arrow) from C. superciliosus at Tsitsikamma. G: Large form with hooked posterior (arrow) from C. superciliosus at Tsitsikamma. H: Large form demonstrating striae (arrow) from Clinus superciliosus at Tsitsikamma. I: Amastigote, (J) sphaeromastigote, (K) short, thick epimastigote, (L) slender epimastigotes, one with two flagella (arrow), (M) slender epimastigote (arrow) with three nuclei and two kinetoplasts, all from Zeylanicobdella arugamensis from Koppie Alleen. $\mathbf{N}$ : Numerous long slender epimastigotes (arrow) in the dorsal sinus of an adult Z. arugamensis from Koppie Alleen. Scale bars: $\mathrm{A}-\mathrm{H}=10 \mu \mathrm{m} ; \mathrm{I}-\mathrm{M}=5 \mu \mathrm{m} ; \mathrm{N}=20 \mu \mathrm{m}$. 
Table 2 Morphometrics of large $(*)$ and small $\left(^{*}\right)$ fish trypanosomes collected at the study sites

\begin{tabular}{|c|c|c|c|c|c|c|c|c|c|}
\hline \multirow{2}{*}{$\begin{array}{l}\text { Fish hosts by } \\
\text { species }\end{array}$} & \multicolumn{9}{|c|}{ Number measured and morphometrics of fish trypanosomes } \\
\hline & No & MA & MP & MK & PK & NL & BW & TBL & $\mathrm{NI}$ \\
\hline \multirow[t]{2}{*}{ Clinus agilis* } & 7 & $37.1 \pm 2.1$ & $33.0 \pm 1.9$ & $21.5 \pm 5.0$ & $14.3 \pm 4.0$ & $4.0 \pm 0.4$ & $9.1 \pm 1.4$ & $70.1 \pm 2.4$ & $0.9 \pm 0.9$ \\
\hline & & $(33.7-40.6)$ & $(31.0-36.8)$ & $(14.6-29.4)$ & $(9.2-20.8)$ & $(3.3-4.4)$ & $(7.1-11.1)$ & $(67.2-74.7)$ & \\
\hline \multirow[t]{2}{*}{ Clinus. cottoides* } & 14 & $36.1 \pm 3.5$ & $35.4 \pm 4.7$ & $19.7 \pm 2.6$ & $18.2 \pm 2.8$ & $4.4 \pm 0.6$ & $10.4 \pm 3.4$ & $71.5 \pm 7.2$ & $1.0 \pm 1.3$ \\
\hline & & $(31.7-42.0)$ & $(24.4-42.9)$ & $(14.9-24.1)$ & $(13.7-22.6)$ & $(3.4-5.3)$ & $(6.9-18.1)$ & $(59.8-81.1)$ & \\
\hline \multirow[t]{2}{*}{ C. cottoides ${ }^{\ddagger}$} & 12 & $15.0 \pm 3.9$ & $19.2 \pm 2.8$ & $11.8 \pm 3.2$ & $7.7 \pm 1.9$ & $3.1 \pm 0.4$ & $4.5 \pm 1.6$ & $34.2 \pm 5.8$ & $1.3 \pm 0.7$ \\
\hline & & $(9.8-22.1)$ & $(15.4-25.2)$ & $(3.3-16.3)$ & $(4.2-10.3)$ & $(2.7-3.6)$ & $(2.6-7.5)$ & $(25.2-46.3)$ & \\
\hline Clinus taurus* & 1 & 33.2 & 29.1 & - & - & 2.6 & 6.2 & 62.3 & 0.9 \\
\hline \multirow[t]{2}{*}{ Clinus superciliosus* } & 22 & $34.6 \pm 5.7$ & $35.5 \pm 3.6$ & $24.7 \pm 4.2$ & $14.0 \pm 3.3$ & $3.5 \pm 0.8$ & $5.8 \pm 1.3$ & $73.3 \pm 11.0$ & $1.0 \pm 0.1$ \\
\hline & & $(27.0-49.2)$ & $(28.1-43.2)$ & $(18.9-30.3)$ & $(9.3-19.2)$ & $(2.2-4.8)$ & $(4.1-8.5)$ & $(55.1-97.7)$ & \\
\hline \multirow[t]{2}{*}{ C. superciliosus ${ }^{\ddagger}$} & 15 & $21.6 \pm 1.8$ & $20.8 \pm 2.5$ & $12.3 \pm 1.9$ & $7.9 \pm 1.2$ & $2.9 \pm 0.6$ & $3.6 \pm 0.8$ & $42.4 \pm 4.1$ & $1.0 \pm 0.1$ \\
\hline & & $(18.2-24.2)$ & $(15.9-24.8)$ & $(10.2-13.9)$ & $(6.6-8.9)$ & $(1.9-4.5)$ & $(2.6-5.7)$ & $(35.1-48.8)$ & \\
\hline Parablennius cornutus ${ }^{\ddagger}$ & 3 & $12.8,15.7,16.5$ & $15.7,16.1,19.5$ & $13.5,13.5,14.4$ & $4.2,4.7,5.1$ & $2.0,2.5,2.8$ & $1.4,2.2,2.5$ & $31.5,32.3,32.5$ & $1.2,1.0,1.2$ \\
\hline
\end{tabular}

Trypanosome measurements in $\mu \mathrm{m} \pm$ standard deviation; range in parenthesis. Abbreviations: No number of trypanosomes measured, MA midnucleus to anterior, $M P$ midnucleus to posterior, $M K$ midnucleus to kinetoplast, $P K$ posterior to kinetoplast, $N L$ nuclear length, $B W$ body width, $T B L$ total body length, $N I$ nuclear index (MP/MA). Free flagellum not visible in most individuals and its measurements are omitted; kinetoplast of one large trypanosome from Clinus taurus also ill-defined and its morphometrics are also omitted.

*fish with large trypanosomes, ${ }^{*}$ fish with small trypanosomes.

C. cottoides at Koppie Alleen (Figure 1B). One of two P. cornutus from the same location had mainly small trypanosomes (Figure 1C) and the larger forms were obscured by lying in thick areas of the blood films, and have been omitted from Table 2. At Tsitsikamma, C. superciliosus appeared to contain in roughly equal proportions, large, small, or a mixture of small and large trypanosomes (Figure 1D-H). Clinus taurus at the same location, however, appeared to be parasitized largely by small trypanosomes, although these were also obscured by lying in thick areas of the blood films, making their measurement difficult (the small forms are also omitted from Table 2).

Small trypanosomes stained pale blue with Giemsa, whereas the larger forms tended to be deeply blue stained, sometimes displaying distinct longitudinal striae, up to 8 or more in number (Figure 1A-C, H). Cytoplasm in both small and large trypanosomes was granulated, often coarsely, while nuclei in both types were normally oval or rectangular, stained pale pink and were wider than long, extending across the full body width (Figure 1A-H). However, in some small trypanosomes, the nucleus was rounded or longer than wide, with its long axis extending along the body length. The nuclear indices (NI values) for small and large trypanosomes were between 0.9 and 1.3 indicating that the nucleus was generally centrally placed or lay just forward of the mid-point of the body (Table 2).

The anterior and posterior extremities of the small trypanosomes were attenuated, often reflexed, or curled (Figure 1A-C). In larger types the anterior end was also attenuated while the posterior extremity was pointed, hooked, bluntly pointed or obtuse (Figure 1D-G), sometimes with coarse granules. The kinetoplast was generally small, rounded, deeply stained and located some distance from the posterior end (Figure 1A, C, D); this distance (PK value) in small forms was approximately half that observed in the larger trypanosomes (see Table 2). In some larger trypanosomes the kinetoplast was surrounded by an unstained halo of cytoplasm.

The undulating membrane was generally well developed in both small and large forms (Figure 1A-H), with eight or fewer undulations in small types and typically eight to 15 waves lying close to the body in larger trypanosomes. Free flagella were generally not easily stained, particularly in the larger forms, with some trypanosomes appearing to have no free flagellum (Figure 1A, B, E-H). When observed, free flagella varied in length, but were typically 7-9 $\mu \mathrm{m}$ long (Figure 1C, D).

\section{Description of trypanosome stages in leeches}

Hayes et al. [15] reported briefly on the developmental stages of trypanosomes in squash preparations and histological sections of the leech, $Z$. arugamensis, from Koppie Alleen. Squashes of 4 adult leeches at 1, 31 and 32 d.p.f., from C. cottoides, and of one adult leech at 30 d.p.f. from $P$. cornutus, all contained trypanosomes. Trypanosome stages were also found in histological sections of $2 / 2$ adult leeches $(1$ d.p.f.) and a juvenile leech ( $<1$ d.p.f.). However, no further details were provided by Hayes et al. [15] and thus the trypanosome developmental stages detected in leeches at that time, and subsequently at Tsitsikamma, are described in detail below.

In leech squashes, the developmental stages of trypanosomes included amastigotes, sphaeromastigotes, short thick epimastigotes, longer thick epimastigotes, long slender 
epimastigotes, a few promastigotes and some metacyclic types. A few large trypomastigote-like forms and a variety of transitional stages were also observed.

Amastigotes were oval or rounded, $5.9 \pm 0.6 \times 4.0 \pm$ $0.6 \mu \mathrm{m}$ (range $=5.0-7.0 \times 3.3-5.5 \mu \mathrm{m})(\mathrm{n}=10)$ and were particularly numerous at 1 d.p.f. (Figure 1I). Division of these stages was not observed. Sphaeromastigotes were also oval or rounded, $5.4 \pm 0.9 \times 3.7 \pm 0.7 \mu \mathrm{m}$ (range $=$ 3.6-6.7 $\times 3.1-5.9 \mu \mathrm{m})$, with a free flagellum of $10.7 \pm$ $3.8 \mu \mathrm{m}$ (range $=5.9-19.4 \mu \mathrm{m})(\mathrm{n}=10)$. Like amastigotes, they were also most numerous in squashes at 1 d.p.f. and were not seen to divide (Figure 1J).

Short thick epimastigotes (Figure $1 \mathrm{~K}$ ), detected at 1 d.p.f., were $10.5 \pm 1.2 \times 2.3 \pm 0.3 \mu \mathrm{m}$ (range $=8.4-12.4 \times$ $1.8-2.9 \mu \mathrm{m}$ ) with a free flagellum of $14.9 \pm 3.2 \mu \mathrm{m}$ (range $=$ 8.5-22.5 $\mu \mathrm{m})(\mathrm{n}=25)$. Their cytoplasm stained pinkishblue, with the posterior region generally more lightly stained than the anterior. The kinetoplast lay posterior to the nucleus, laterally to this structure, or close to its anterior margin. A short undulating membrane was detected in most, but not all, short epimastigotes. Some were binucleate, while others had two kinetoplasts, suggesting division. Longer, thick epimastigotes, $18.5 \pm 4.1 \times 2.4 \pm$ $0.4 \mu \mathrm{m}$ (range $=12.7-23.7 \times 2.1-3.2 \mu \mathrm{m})$, with a free flagellum of $22.9 \pm 5.3 \mu \mathrm{m}$ (range 10.7-30.3 $\mu \mathrm{m})(\mathrm{n}=10)$ were found in low numbers in smears at 1, 30-32 d.p.f. Cytoplasm and nuclei were stained as in shorter epimastigotes, with some of these stages also having 2 kinetoplasts.

Long slender epimastigotes, $17.4 \pm 3.1 \times 1.4 \pm 0.2 \mu \mathrm{m}$ (range $=12.0-26.1 \times 0.9-1.8 \mu \mathrm{m})$, with a free flagellum of $24.1 \pm 4.1 \mu \mathrm{m}$ (range $=13.2-31.1 \mu \mathrm{m}) \quad(\mathrm{n}=25)$, were detected in large numbers, especially at 1 d.p.f. (Figure 1L, $\mathrm{M})$. Their posterior end was often strongly tapered, but blunt posteriors were also present. As in short thick types, the kinetoplast lay just anterior, posterior, or lateral to the nucleus. Binucleate, or sometimes trinucleate, long slender epimastigotes, often with two kinetoplasts and flagella, indicated division (Figure 1L, M). Promastigote stages, with the kinetoplast well forward of the anterior margin of the nucleus, were observed only rarely (at 1 d.p.f.). Early metacyclic trypomastigotes, with the kinetoplast lying posterior, were not numerous either, but were observed at 1, 30-32 d.p.f..

A few large, broad, poorly preserved transitional forms resembling blood trypomastigotes from fishes were seen in leeches squashed at 30-32 d.p.f. (not illustrated). These varied greatly in appearance, and were larger than any other stages observed in leeches. The cytoplasm of these broad forms stained dark blue, with darkly stained granules; the nucleus was lightly stained pink, usually oval or rounded, with the kinetoplast in close proximity. An undulating membrane and free flagellum were visible in some individuals, while others appeared to be undergoing transformation into rounded forms.
Developmental stages of trypanosomes were also found in histological sections of two adult $Z$. arugamensis at 1 d.p.f. and one juvenile at $<1$ d.p.f. at Koppie Alleen. These included a few amastigotes and short thick epimastigotes, but long slender epimastigotes predominated. Amastigotes were noted in the crop of one adult leech, and these, as well as short thick, and long slender epimastigotes occurred in the intestine, although no attachment to the epithelial lining of this structure was evident. Binucleate, long slender epimastigotes, presumably undergoing division, were seen in the intestine of the second adult leech. Epimastigotes were also observed in the intestine of the juvenile leech, but were less abundant and lacked evidence of division. Numerous long, slender, epimastigotes were located in the dorsal sinus (dorsal coelomic cavity) of both adult leeches (Figure 1N), although none was seen adjacent to the proboscis.

\section{Sequence identification, alignment and phylogenetic analysis}

The longest sequences were obtained from C. superciliosus whole blood containing large or small trypanosomes, from Tsitsikamma, and from Giemsa-stained squashes of the leech, Z. arugamensis, containing numerous epimastigotes, taken from C. cottoides at Koppie Alleen and C. superciliosus at Tsitsikamma. The 900 bp $18 \mathrm{~S}$ rDNA sequences from the fishes or the leeches were identical and general BLAST searches via GenBank showed them all to be most similar to two marine trypanosomes, T. murmanense [GenBank:DQ016616] and T. pleuronectidium [GenBank:DQ016618] [18].

As the trypanosome $18 \mathrm{~S}$ rDNA sequences obtained from C. superciliosus and Z. arugamensis were identical, only a single sequence [GenBank:KF871790] was used to represent the parasite during phylogenetic reconstruction (Figure 2, where it is identified as that of Trypanosoma nudigobii - see the Discussion below). The overall topology of the phylogenetic trees generated was identical irrespective of the analyses employed (Figure 2). All fish trypanosomes comprised a single clade, with amphibian trypanosomes as a sister group. The fish trypanosome clade was further divided into three subclades. Two distinct clades represented the trypanosomes of freshwater and marine fishes, while the third clade contained just two species, Trypanosoma chelodinae [GenBank:AF297086] and Trypanosoma binneyi [GenBank:AJ620565], which parasitize a turtle and the platypus respectively. Trypanosoma nudigobii nested within the marine fish clade and appeared to be a sister species/lineage basal to a small clade which contained T. murmanense and T. pleuronectidium, confirming a close relationship with these species. The South African trypanosomes thus appeared more closely related to $T$. murmanense and $T$. pleuronectidium than to the Senegalese species Trypanosoma senegalense 


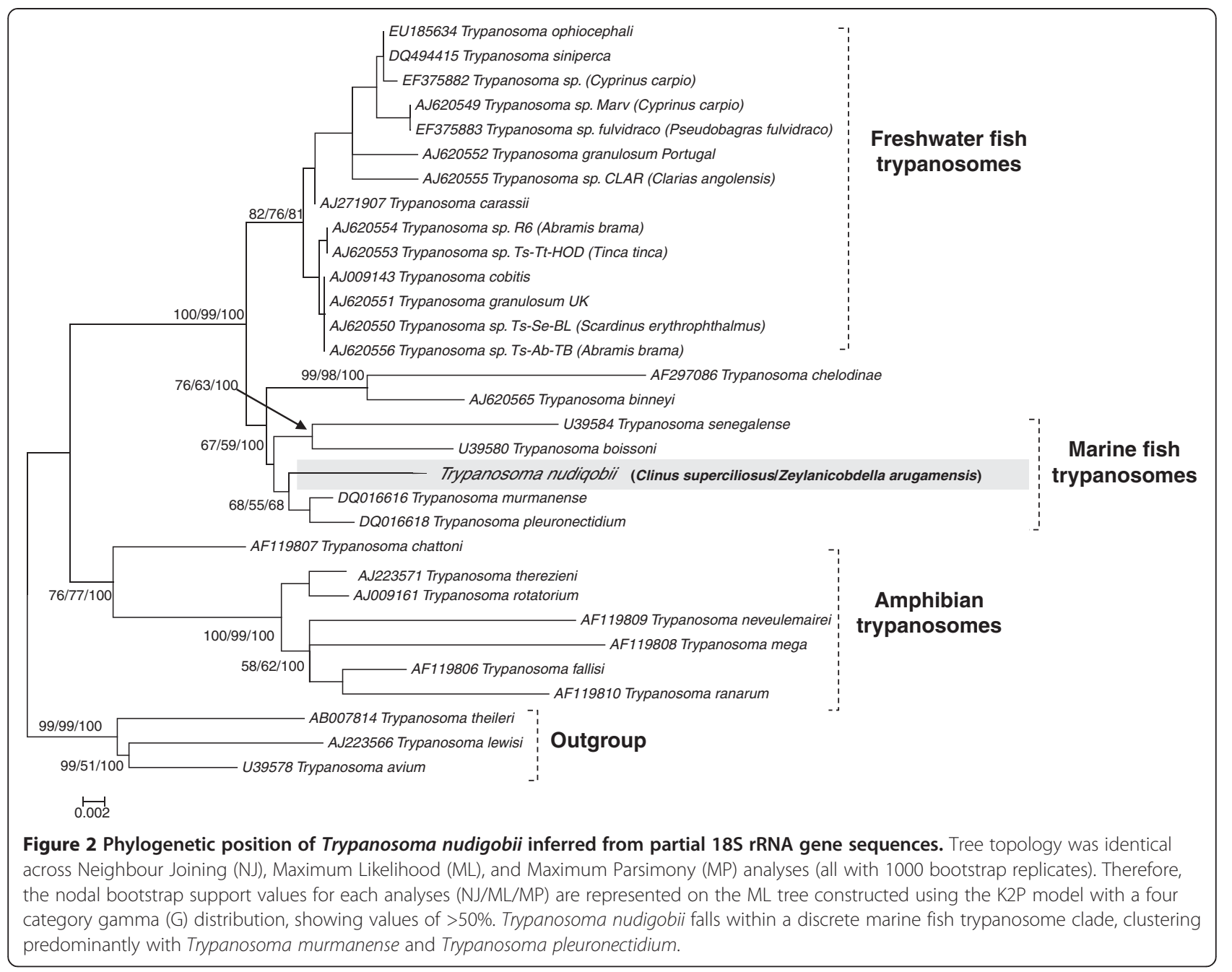

[GenBank:U39584] (previously known as Trypanosoma trigla senegalensis [see [18,28]]) and Trypanosoma boissoni [GenBank:U39580].

Voucher specimens of trypanosome stages in a blood film from C. superciliosus (NMP P 361) collected on 2008/03/30 from Tsitsikamma National Park and a leech squash (NMP P 362) collected on 2003/10/09 from De Hoop Nature Reserve have been deposited in the National Museum in Bloemfontein, South Africa. DNA samples from the leech, Z.arugamensis, are to be sequenced, as part of another project, and the resultant sequence data will be made available on GenBank.

\section{Discussion}

Fantham [10] described two trypanosome species from the blood and internal organs of Caffrogobius nudiceps in the South African region of Kalk Bay. The larger species, Trypanosoma nudigobii, with a short free flagellum and a body with tapering ends, measured $60-85 \mu \mathrm{m}$ long by 6.6$7.5 \mu \mathrm{m}$ wide. The undulating membrane was usually narrow, cytoplasm was granular, and normally ten striae (myonemes) were present. An oval, pale staining, nucleus extended across the body and the kinetoplast was small and rounded, often with a pale halo. The smaller trypanosome species, Trypanosoma capigobii, also had pointed extremities, but a shorter and narrower body, measuring $42-60 \mu \mathrm{m}$ long by $2-4.4 \mu \mathrm{m}$ wide. Five striae were usually observed, and the centrally placed nucleus lay with its long axis parallel to that of the trypanosome body. The undulating membrane arose close to the kinetoplast, which was small and distinct. Later, Fantham [11] found T. capigobii in the same host fish (G. nudiceps) at St. James, except that the body was $60-80 \mu \mathrm{m}$ long by $2.7-4 \mu \mathrm{m}$ wide, and there was "hardly any" free flagellum.

Fantham [11] also observed a trypanosome in Blennophis anguillaris and Parablennius cornutus. The body of this species, Trypanosoma blenniclini, was "long and sinuous with a narrow undulating membrane" and it measured 50-77 $\mu \mathrm{m}$ long by $3-7 \mu \mathrm{m}$ wide. No free flagellum was detected, but numerous striae and coarse granules were recorded in the cytoplasm, rendering it dense in appearance. The nucleus was oval or rounded, and extended 
across the body width, while the kinetoplast was situated 6-9 $\mu \mathrm{m}$ from the posterior end, which was often bluntly rounded. This third trypanosome species (T. blenniclini) was thus intermediate in size between the original descriptions of T. nudigobii and T. capigobii, and its cytoplasm and nucleus had features of both previously named trypanosome species.

In the current case, trypanosomes were located in a clinid (Clinus agilis) captured at Mouile Point, which lies west of Kalk Bay and St James, and in further clinids (Clinus cottoides, Clinus superciliosus and Clinus taurus) and a blenniid (P. cornutus) at Koppie Alleen and/or Tsitsikamma, which both lie east of Fantham's collection sites $[10,11]$. Surprisingly, however, no trypanosomes were located in $C$. nudiceps, the type host of T. nudigobii and $T$ capigobii, although present in P. cornutus, one of the type hosts of $T$. blenniclini $[10,11]$. In addition, it was evident that trypanosomes were detected in fishes in October 2003 and April 2008 and 2010, but not in April 2013. This lack of trypanosomes in April 2013 reflected earlier observations in South Africa, when no flagellates were found in intertidal fishes along the southern coast between 1999 and 2003 [29-33].

Although "small" and "large" trypanosomes had been separated by total body length (TBL) in the current study (Table 2), there was clearly overlap among the TBL of small or large trypanosomes across the five species of fish hosts parasitized (Table 2). There was also overlap between the highest values in smaller forms and the lowest values in large forms for midnucleus to posterior, midnucleus to kinetoplast, nuclear length, and body width (MP, MK, NL and BW values) [27] (see Table 2). Some trypanosomes resembled Fantham's smaller T. capigobii [10] in size, having a mean body length up to $42.4 \mu \mathrm{m}$ and body width up to $4.5 \mu \mathrm{m}$. Others more closely resembled $T$. nudigobii, the larger T. capigobii and T. blenniclini $[10,11]$, having a mean body length of $73.3 \mu \mathrm{m}$, although mean body width (up to $10.4 \mu \mathrm{m}$ in C. cottoides trypanosomes) could exceed that of Fantham's three species. The body shape of the trypanosomes matched those of Fantham's three species, the free flagellum also tended to be short or not clearly visible, cytoplasm was granular and striae were often prominent, the nucleus was rounded to oval, and the kinetoplast small and rounded, and sometimes surrounded by a clear halo. Commonality was thus observed among the morphometric features of the current trypanosomes and all three of Fantham's $[10,11]$ species, suggesting that they might all belong to one pleomorphic species, with the smaller trypanosomes representing immature stages of the larger forms. The suspected division stages amongst the smaller trypanosomes observed in two fish species appeared different from the traditional patterns of division seen in other fish trypanosomes [1,34], but further observations are required before any conclusions can be drawn.
There were no likely vectors of South African marine fish trypanosomes reported by Fantham [10,11], but Hayes et al. [15] briefly noted trypanosome stages in the leech Zeylanicobdella arugamensis. Since most leeches were taken from infected fishes, the developmental forms of trypanosomes found in leech squashes and histological preparations were likely those of flagellates detected in fish blood films. These stages were found in both a juvenile and adult leeches, suggesting that trypanosomes were acquired at a young age and retained into adulthood in these annelids.

The developmental forms in Z. arugamensis were typical of those reported from marine leeches in the northern hemisphere $[2-7,35,36]$. Their variety and their distribution days post feeding (d.p.f.) suggested a mixture of old and new infections. Dividing epimastigotes were evident at 1 (old infection?), 30, 31 and 32 d.p.f (recent infections?), suggesting that these are the dominant divisional stages of the South African trypanosomes. Epimastigotes were also the main divisional stages of Trypanosoma rajae Laveran and Mesnil, 1902 in Pontobdella muricata (L.) $[35,36]$, in contrast to the amastigotes and sphaeromastigotes of Trypanosoma giganteum Neumann, 1909 in P. muricata [4], Trypanosoma murmanensis in Johanssonia sp. [5] and Trypanosoma cotti Brumpt and Lebailly, 1904 in Calliobdella punctata van Beneden and Hesse, 1863 [6]. The tetranucleate stages reported by Robertson [35] were not observed.

In histological sections of the leeches examined in the present study, amastigotes occurred in the crop, and both these and a variety of epimastigote stages were observed in the intestine. The few metacyclic trypomastigotes seen in squashes were not identified in sections. Robertson [35,36] and Khan [5,7] described a range of polymorphic forms from the intestine of leeches in what they referred to as the middle stages of digestion. Amastigotes and sphaeromastigotes were reported from the crop during the early phase of digestion, while metacyclic trypomastigotes were generally observed in the proboscis following complete digestion of the blood meal $[5,7,35,36]$. Brumpt [3] also reported a variety of stages of $T$. cotti from the intestine of leeches, but, as in our study, none was observed in the proboscis. As reported by Hayes et al. [15], migration to and invasion of the leech proboscis sheath by fish trypanosomes has not been elucidated fully. However, large numbers of long slender epimastigotes were observed in the dorsal sinus of $Z$. arugamensis, a rhyncobdellid leech [37]. This sinus, which includes the dorsal blood vessel, and connects through a series of sinuses and ducts to the medial haemocoelomic sinus adjacent to the proboscis, may thus be the means by which the flagellates are transported, or migrate to the proboscis sheath [15].

Analysis of the $18 \mathrm{~S}$ rDNA sequences derived from several fish species revealed only one type of sequence 
was present, irrespective of whether the fishes contained small or large trypanosomes. Identical sequences were secured from Giemsa-stained smears containing predominantly epimastigote stages taken from leeches, $Z$. arugamensis, captured on trypanosome-parasitized fishes at Koppie Alleen and at Tsitsikamma. These results demonstrated that only one pleomorphic trypanosome species was likely present in the fishes and leeches sampled. In addition, since only trypanosome developmental stages, especially epimastigotes, were found in the leech squashes used for DNA analysis, that is, no blood trypomastigotes, the matching sequences indicate that $Z$. arugamensis must be the vector for the fish trypanosome, at least at Koppie Alleen and at Tsitsikamma.

The trypanosome sequences generated in this study fell into a discrete clade consisting of trypanosomes that parasitize marine fishes. However, they appeared more closely related to Trypanosoma murmanense and Trypanosoma pleuronectidium, both trypanosomes of marine teleosts, especially Atlantic cod, Gadus morhua L. off Norway [18], rather than to the two African marine fish trypanosomes in this clade, Trypanosoma senegalense and Trypanosoma boissoni, from a teleost and an elasmobranch respectively in Senegal [18,28]. The data in the current study support the existence of a predominant fish clade with distinct marine and freshwater subclades, as suggested by Gibson et al. [16], Kalsbakk and Nylund [18] and $\mathrm{Gu}$ et al. [20]. However, an aquatic tetrapod subclade containing $T$. binneyi, from the platypus and $T$. chelodinae from turtles, also falls within the clade of trypanosomes from marine and freshwater fishes, and this occurs in other phylogenetic analyses such as those of Karlsbakk and Nylund [18] and Gu et al. [20]. The seemingly anomalous phylogenetic position of this tetrapod clade could simply arise from insufficient taxon sampling and gene sequence information, leading to poor phylogenetic resolution. But more interestingly, it could indicate host swapping leading to parasite species divergence; a lack of fidelity of leech vectors, feeding on a multitude of vertebrate host species, might explain this. Although this separation of the fish clades was not the focus of the current study, only through further sampling with a greater number of species will this issue be resolved.

\section{Conclusions}

Our observations strongly suggest that, despite the variety of trypanosome morphometric types observed by Fantham $[10,11]$ and particularly by us in the current study, the marine fish trypanosomes are likely of one genotype and thus, one pleomorphic species, with the leech Z. arugamensis as its vector. We suggest, therefore, that all three species of Fantham $[10,11]$ and our trypanosomes are Trypanosoma nudigobii, Fantham's first named species, and we recommend the following nomenclatural correction:
Trypanosoma nudigobii Fantham, 1919 (syn. Trypanosoma capigobii Fantham, 1919; syn. Trypanosoma blenniclini Fantham, 1930) in the marine fishes Caffrogobius nudiceps (type host), Blennophis anguillaris, Clinus agilis, Clinus cottoides, Clinus taurus and Parablennius cornutus, and the leech (vector), Zeylanicobdella arugamensis. As far as we are aware, this is the first study to link the vertebrate hosts and vector of a marine fish trypanosome by morphological and molecular means.

\section{Competing interests}

The authors declare that they have no competing interests.

\section{Authors' contributions}

All authors conceived and designed the project, participated in general data analysis and in drafting the manuscript. PMH, NJS and AJD carried out the field work, prepared and examined films, squashes and histological material, and PMH, SPL and WCG conducted most of the molecular analysis. All authors read and approved the final manuscript.

\section{Acknowledgements}

We are grateful for the assistance of Dr Maryke Ferreira (University of Johannesburg) with fieldwork at Tsitsikamma National Park, and of Dr Emily Adams (University of Bristol) and Mr George Yartey (Kingston University) with molecular techniques. We would also like to thank the staff of the DNA Sequencing Facility at the Natural History Museum for providing the service to clean and sequence PCR products generated for this project. Financial assistance from the South African National Research Foundation (NRF) towards this research is hereby acknowledged (project IFR2011040100022). Opinions expressed, and conclusions arrived at, are those of the authors and are not necessarily to be attributed to the NRF.

\section{Author details}

${ }^{1}$ Department of Life Sciences, Natural History Museum, London SW7 5BD, UK. ${ }^{2}$ Molecular Parasitology Laboratory, School of Life Sciences, Kingston University, Kingston upon Thames, Surrey KT1 2EE, UK. ${ }^{3}$ Water Research Group (Ecology), Unit for Environmental Sciences and Management, North-West University, Potchefstroom Campus, Potchefstroom 2520, South Africa. ${ }^{4}$ School of Biological Sciences, University of Bristol, Bristol BS8 1UG, UK.

Received: 19 September 2013 Accepted: 11 December 2013 Published: 24 January 2014

References

1. Woo PTK: Diplomonadida (Phylum Parabasalia) and Kinetoplastea (Phylum Euglenozoa). In Fish Diseases and Disorders. Volume 1. Protozoan and Metozoan Infections. 2nd edition. Edited by Woo PKT. Oxfordshire: CABI; 2006:46-115.

2. Brumpt E: Contribution á l'étude d'évolution des hémogrégarines et des trypanosomes. C R Soc Biol 1904, 57:165-167.

3. Brumpt E: Mode de transmission et evolution des trypanosomes des poisons. Descriptions de quelques espésces de trypanoplasmes des poisons d'eau douce. Trypanosome d'un crapaud Africain. C R Soc Biol 1906, 60:162-164

4. Neumann RO: Studien über protozoische Parasiten im Blute von Meeresfischen. Z Hyg Infektionskr 1909, 64:1-112.

5. Khan RA: The life cycle of Trypanosoma murmanensis Nikitin. Can J Zool 1976, 54:1840-1849.

6. Khan RA: A redescription of Trypanosoma cotti Brumpt and Lebailly, 1904 and its development in the leech, Calliobdella punctata. Ann Parasitol 1978, 53:461-466.

7. Khan RA: Longevity of Trypanosoma murmanensis in the leech, Johanssonia sp. Can J Zool 1978, 56:2061-2063.

8. Karlsbaak E: A trypanosome of Atlantic cod, Gadus morhua L., transmitted by the marine leech Calliobdella nodulifera (Malm, 1863) (Piscicolidae). Parasitol Res 2004, 93:155-158. 
9. Karlsbaak $E_{\text {, Haugen }}$, Nylund $\mathrm{A}$ : Morphology and aspects of growth of a trypanosome transmitted by the marine leech Johanssonia arctica (Piscicolidae) from Northern Norway. Folia Parasitol 2005, 52:209-215.

10. Fantham HB: Some parasitic protozoa found in South Africa - II. S Afr J Sci 1919, 16:185-191.

11. Fantham HB: Some parasitic protozoa found in South Africa - XIII. S Afr J Sci 1930, 27:376-390.

12. Paperna I: Parasites, Infections and Diseases of Fish in Africa. An update. Rome: Food and Agriculture Organization of the United Nations; 1996. CIFAT Technical Paper.

13. Smit NJ, Eiras JC, Ranzani-Paiva MJT, Davies AJ: A Desseria sp. from flathead mullet in South Africa. J Mar Biol Ass UK 2002, 82:675-676.

14. Yeld EM, Smit NJ: A new species of Trypanosoma (Kinetoplastida: Trypanosomatidae) infecting catsharks from South Africa. J Mar Biol Ass UK 2006, 86:829-833.

15. Hayes PM, Smit NJ, Seddon AM, Wertheim DF, Davies AJ: A new fish haemogregarine from South Africa and its suspected dual transmission with trypanosomes by a marine leech. Folia Parasitol 2006, 53:241-248.

16. Gibson WC, Lom J, Peckova H, Ferris VR, Hamilton PB: Phylogenetic analysis of freshwater fish trypanosomes from Europe using ss rRNA gene sequences and random amplification of polymorphic DNA. Parasitology 2005, 130:405-412.

17. Davies AJ, Gibson WC, Ferris V, Basson L, Smit NJ: Two genotypic groups of morphologically similar fish trypanosomes from the Okavango Delta, Botswana. Dis Aquat Org 2005, 66:215-220.

18. Karlsbakk E, Nylund A: Trypanosomes infecting cod Gadus morhua L. in the North Atlantic: a resurrection of Trypanosoma pleuronectidium Robertson, 1906 and delimitation of T. murmanense Nikitin, 1927 (emend.), with a review of other trypanosomes from North Atlantic and Mediterranean teleosts. Syst Parasitol 2006, 65:175-203.

19. Figueroa F, Mayer WE, Lom J, Dyková I, Weller M, Pecková H, Klein J: Fish trypanosomes: their position in kinetoplastid phylogeny and variability as determined from $12 \mathrm{~s}$ rRNA kinetoplast sequences. J Eukaryot Microbiol 1999, 46:473-481.

20. Gu Z, Wang J, Ke X, Liu Y, Liu X, Gong X, Li A: Phylogenetic position of the freshwater fish trypanosome, Trypanosma ophiocephali (Kinetoplastida) inferred from the complete small subunit ribosomal RNA gene sequence. Parasitol Res 2010, 106:1039-1042.

21. Chanseau M, Bosc S, Galiay E, Oules G: L'utilisation de I'huile de clou de girofle comme anesthésique pour les smolts de saumon Atlantique (Salmo salar L.) et comparaison de ses effets avec ceux du 2phénoxyethanol. Bull Fr Peche Piscic 2002, 365/366:579-589.

22. Smit NJ, Van As JG, Basson L: A redescription of the adult male and larvae of Gnathia africana Barnard, 1914 (Gnathiidae: Crustacea: Isopoda) from southern Africa. Folia Parasitol 1999, 46:229-240.

23. Hamilton PB: Investigations in Trypanosome Diversity and Evolution Using Molecular Phylogenetic Analysis, PhD thesis. Bristol: University of Bristol, School of Biological Sciences; 2003.

24. Hall TA: BioEdit: a user-friendly biological sequence alignment editor and analysis program for Windows 95/98/NT. Nucl Acids Symp Ser 1999, 41:95-98.

25. Tamura K, Peterson D, Peterson N, Steche G, Nei M, Kumar S: MEGA5: molecular evolutionary genetics analysis using maximum likelihood, evolutionary distance, and maximum parsimony methods. Mol Biol Evol 2011, 28:2731-2739.

26. Hayes PM, Wertheim DF, Smit NJ, Seddon AM, Davies AJ: Threedimensional visualization of developmental stages of an apicomplexan fish blood parasite in its invertebrate host. Parasit Vectors 2011, 4:219.

27. Becker CD, Overstreet RM: Haematozoa of marine fishes from the northern Gulf of Mexico. J Fish Dis 1979, 2:469-479.

28. Maslov DA, Lukeš J, Jirku M, Simpson L: Phylogeny of trypanosomes as inferred from the small and large subunit rRNAs: implications for the evolution of parasitism in the trypanosomatid protozoa. Mol Biochem Parasitol 1996, 75:197-205.

29. Smit NJ, Davies AJ: New host records for Haemogregarina bigemina from the coast of Southern Africa. J Mar Biol Ass UK 1999, 79:933-935.

30. Smit NJ, Davies AJ: An encapsulated haemogregarine from the evileye pufferfish in South Africa. J Mar Biol Ass UK 2001, 81:751-754.

31. Davies AJ, Smit NJ: The life cycle of Haemogregarina bigemina (Adeleina: Haemogregarinidae) in South African hosts. Folia Parasitol 2001, 48:169-177.

32. Davies AJ, Reed CC, Smit NJ: An unusual intraerythrocytic parasite of Parablennius cornutus from South Africa. J Parasitol 2003, 89:913-917.
33. Smit NJ, Van As JG, Davies AJ: Taxonomic re-evaluation of the South African fish haemogregarine Desseria fragilis. J Parasitol 2003, 89:151-153.

34. Burreson EM, Karlsbakk E: Multiplication of Trypanosoma pacifica (Euglenozoa: Kinetoplastea) in English sole, Parophrys vetulus, from Oregon coastal waters. J Parasitol 2007, 93:932-933.

35. Robertson M: Studies on a trypanosome found in the alimentary canal of Pontobdella muricata. Proc R Phys Soc Edinburgh 1907, 17:83-108.

36. Robertson M: Further notes on a trypanosome found in the alimentary tract of Pontobdella muricata. Q J Microsc Sci 1909, 54:119-139.

37. De Silva PHDH: Zeylanicobdella arugamensis gen. nov. and sp. nov. from Arugam Kalapu, Eastern Province, Ceylon. Spolia Zeylan 1963, 30:46-53.

doi:10.1186/1756-3305-7-50

Cite this article as: Hayes et al:: Morphological and molecular characterization of a marine fish trypanosome from South Africa, including its development in a leech vector. Parasites \& Vectors 2014 7:50.

\section{Submit your next manuscript to BioMed Central and take full advantage of:}

- Convenient online submission

- Thorough peer review

- No space constraints or color figure charges

- Immediate publication on acceptance

- Inclusion in PubMed, CAS, Scopus and Google Scholar

- Research which is freely available for redistribution

Submit your manuscript at www.biomedcentral.com/submit
C) Biomed Central 